\title{
Efektivitas Media Leaflet dan Film dalam Peningkatan Pengetahuan Pubertas di SMP N 226 Pondok Labu
}

\author{
Yanti Harjono Hadiwiardjo*, Mila Citrawati, Citra Ayu Aprilia \\ Universitas Pembangunan Nasional "Veteran” Jakarta, Jl. RS Fatmawati, Pondok Labu, \\ Jakarta Selatan \\ *corresponding author, e-mail: yantiharjono@gmail.com
}

Received: 14/01/2019; Published: 18/03/2020

\begin{abstract}
Background: Adolescent is a trantition phase from childhood to adulthood. Knowledge about puberty is important during this phase. If there is no sufficient information about it, it could cause several problems such as adolescence growth and development failure and healt problems. Health promotion to increase awareness of puberty is definitely needed by junior high students aged around 8 to 14 years old. Puberty health promotion could be delivered through visual media such as leaflet or audiovisual media such as animation film. The aim of this study was to discover effectivity of leaflet and animation film in increasing puberty awareness in students of Public Junior High School 226, Pondok Labu, South Jakarta. Method: This study was a quasi experiment with one group pre test-posttest design. Population of this study was whole students of $7^{\text {th }}$ grade Public Junior High School 226. Sampling technique used was total sampling as many as 256 students. Data was analyzed by Wilcoxon test to find out effectivity of leaflet and animation film, meanwhile Mann Whitney test was used to discover effectivity between leaflet and animation film. Results: Both leaflet and animation film were effective to improving knowledge for adolescent ( $p$-value<0,001). Conclusion: Either leaflet or animation film increased puberty awareness of students. There was no effectivity difference between both media in increasing puberty awareness of students at Public Junior High School 226.
\end{abstract}

Key words: film; leaflet; puberty; knowledge

Copyright $(2013$ Universitas Ahmad Dahlan. All rights reserved.

1. Pendahuluan

Masa remaja atau masa remaja adalah suatu fase tumbuh kembang yang dinamis dalam kehidupan seorang individu yang mana merupakan periode transisi dari masa kanakkanak ke masa dewasa yang memiliki tanda-tanda seperti percepatan perkembangan fisik, mental, emosional, dan sosial. Remaja merupakan fase di antara anak-anak dan dewasa. Masa remaja adalah masa di antara masa anak dan dewasa. Definisi yang lebih luas dan lebih inklusif dari masa remaja penting untuk perkembangan sistem hukum, politik sosial dan pelayanan yang tepat. Daripada umur 10-19 tahun, definisi 10-24 tahun lebih sesuai dengan perkembangan remaja dan pengertian umum dari fase ini.(1)

Pubertas merupakan tanda dimulainya awal masa pertumbuhan dan perkembangan biologis remaja dimana terjadi suatu proses pendewasaan tubuh yang memiliki tujuan akhir mampu bereproduksi seksual. Pada fase tersebut tubuh sedang mengalami perubahan secara besar-besaran dari struktur tubuh anak-anak menjadi struktur tubuh orang dewasa. Pubertas juga dapat diartikan masa ketika seseorang anak mengalami perubahan pada fisik, psikis dan pematangan fungsi seksual. Waktu mulai dan berakhirnya pubertas sangatlah bervariasi. Pubertas mulai dari 8 tahun hingga 14 tahun dan waktu berakhir dari 17 tahun hingga 21 tahun. Ini berarti masa pubertas biasa dimulai pada masa remaja awal yaitu pada remaja yang beranjak sekolah seperti remaja di Sekolah Menengah Pertama khususnya kelas VII.(2) 
Pubertas adalah masa dimana kematangan kerangka dan seksual terjadi dengan pesat terutama pada awal masa remaja. Kematangan seksual ditandai dengan perubahan pada seks primer (Primary Sex Characteristics) dan perubahan pada seks sekunder (Secondary Sex Characteristics) yang menyertai rangkaianperubahan pada masa remaja. Salah satu periode dari perkembangan manusia adalah masa remaja yang merupakan masa peralihan dari masa kanak-kanak ke masa dewasa yang meliputi perubahan biologis, perubahan psikologis dan perubahan sosial. Masa remaja pada umumnya dimulai pada usia 10-13 tahun dan berakhir pada usia 18-22 tahun.(3)

Menurut Survey Demografi dan Kesehtan Indonesia (SDKI) 2017, remaja perempuan paling banyak mengetahui perubahan fisik pada laki-laki adalah perubahan suara, tulang jakun menonjol, ada tumbuhnya rambut di sekitar wajah, alat kelamin, ketiak dan sebagainya. Remaja laki-laki paling banyak mengetahui perubahan fisik pada perempuan adalah payudara membesar, mulai haid dan tumbuh rambut di sekitar alat kelamin atau hal ini memperlihatkan bahwa masih terdapat tanda-tanda perubahan fisik yang masih banyak belum diketahui oleh remaja perempuan maupun remaja laki-laki sehingga masih diperlukan adanya pemberian informasi atau pengetahuan mengenai pubertas.(4) Adapun penelitian yang terdahulu yang menyatakan bahwa terdapat pengaruh penyuluhan terhadap pengetahuan remaja perempuan tentang tanda-tanda pubertas di kelas VII SMP.(5)

Pemberian promosi kesehatan dapat diberikan melalui media visual seperti leaflet maupun media audiovisual. Dalam pendidikan kesehatan, media yang mudah untuk dipahami dan menarik audien adalah media film.(6) Terlepas dari kekurangan dan kelebihan dari media leaflet dan media film, kedua media tersebut merupakan pendukung promosi kesehatan yang baik. Maka perlu dilakukan penelitian efektifitas antara kedua media tersebut dalam promosi kesehatan untuk meningkatkan pengetahuan pubertas pada siswa SMP.(7) Penelitian ini dilakukan di SMP 226 karena sekolah berada di sekitar UPN "Veteran" Jakarta sehingga dapat merupakan manfaat institusi terhadap lingkungan. Berdasarkan latar belakang di atas maka peneliti bertujuan untuk mengetahui efektivitas media leaflet dan media film dalam peningkatan pengetahuan pubertas di sekolah menengah pertama negeri (SMPN) 226 Pondok Labu Jakarta Selatan.

\section{Metode Penelitian}

Penelitian ini merupakan penelitian kuantitatif quasi experiment dengan design one group pretest-posttest design. Data dikumpulkan dengan menggunakan kuesioner yang telah diuji validitas dan reliabilitasnya. Kuesioner pengetahuan mengenai pubertas terdiri dari 15 pertanyaan yang terdiri dari tanda pubertas, faktor yang mempengaruhi pubertas dan higienitas organ reproduksi. Sebelum pengumpulan data dilakukan pemberian informed consent yang berisi maksud dan tujuan penelitian serta persetujuan dari siswa untuk mengikuti penelitian. Media promosi kesehatan yang digunakan dalam penelitian ini adalah media leaflet dan media film. Media leaflet dan film dibuat oleh peneliti sendiri dan sesuai dengan kuesioner yang ditanyakan kepada siswa.

Populasi pada penelitian ini adalah seluruh siswa kelas VII SMPN 226. Teknik sampling yang digunakan pada penelitian ini adalah sampel jenuh sebanyak 256 siswa yaitu terdiri dari 150 perempuan dan 106 laki-laki. Jumlah siswa yang diberi promosi kesehatan dengan menggunakan media leaflet sebanyak 148 siswa dan media film sebanyak 108 siswa. Variabel bebas penelitian ini adalah pemberian promosi kesehatan dengan media leaflet dan media film, sedangkan variabel terikat adalah nilai pengetahuan pubertas. Analisis data dilakukan untuk mengunakan analisis univariat dan bivariat. Analisis univariat dilakukan untuk mendeskripsikan nilai pengetahuan mengenai pubertas pada siswa yang diberi edukasi. Analisis bivariat dilakukan dengan menganalisis nilai pengetahuan sebelum dan sesudah pada siswa yang diberi promosi kesehatan menggunakan media leaflet dengan uji $\mathrm{T}$ berpasangan atau uji Wilxocon sebagai uji alternatif. 


\section{Hasil dan Pembahasan}

3.1 Hasil

Tabel 1. memperlihatkan karakteristik responden di SMP Negeri 226 Pondok Labu Jakarta Selatan dimana siswa yang diberi promosi kesehatan dengan menggunakan media leaflet lebih banyak perempuan $(63,5 \%)$ dan yang diberi promosi kesehatan dengan menggunakan media film lebih banyak perempuan $(51,9 \%)$. Usia siswa yang diberi promosi kesehatan dengan media leaflet lebih banyak yang berusia 12 tahun $(60,8 \%)$ dan usia siswa yang diberi promosi kesehatan dengan media film lebih banyak berusia 12 tahun $(55,56 \%)$.

Tabel 1. Karakteristik Responden Berdasarkan Jenis Kelamin dan Umur

\begin{tabular}{lccccc}
\hline \multicolumn{2}{c}{ Variabel } & \multicolumn{2}{c}{ Leaflet } & \multicolumn{2}{c}{ Film } \\
\cline { 3 - 6 } & & $\mathbf{n}$ & $\%$ & $\mathbf{n}$ & $\%$ \\
\hline \multirow{2}{*}{ Jenis kelamin } & Perempuan & 94 & 63,5 & 56 & 51,9 \\
& Laki-Laki & 54 & 36,5 & 52 & 48,1 \\
\multirow{3}{*}{ Umur } & 11 & 4 & 2,7 & 3 & 2,78 \\
& 12 & 90 & 60,8 & 60 & 55,56 \\
& 13 & 50 & 33,8 & 42 & 38,88 \\
& 14 & 4 & 2,7 & 3 & 2,78 \\
\hline
\end{tabular}

Tabel 2. menunjukkan terdapat perbedaan pengetahuan pubertas sebelum dan sesudah diberi promosi kesehatan dengan media leaflet pada siswa di SMPN 226 Pondok Labu Jakarta Selatan $(p$-value $<0,05)$ dan media leaflet efektif meningkatkan pengetahuan pubertas pada siswa di SMPN 226 Pondok Labu Jakarta.

Tabel 2. Perbandingan Nilai Pengetahuan Pubertas Sebelum dan Sesudah Promosi Kesehatan dengan Media Leaflet di SMPN 226 Pondok Labu Jakarta Selatan

\begin{tabular}{lcccc}
\hline & $\mathrm{N}$ & $\begin{array}{c}\text { Median } \\
\text { (Minimum-Maksimum) }\end{array}$ & Rerata \pm SD & $\begin{array}{c}\mathrm{p}- \\
\text { value }\end{array}$ \\
\hline Pengetahuan sebelum promosi kesehatan & 148 & $86,67(40-100)$ & $86,13 \pm 12,98$ & 0,000 \\
Pengetahuan sesudah promosi kesehatan & 148 & $93,33(20-100)$ & $89,82 \pm 14,09$ & 0,000 \\
\hline
\end{tabular}

Berdasarkan Tabel 3. dapat terlihat bahwa terdapat perbedaan pengetahuan pubertas sebelum dan sesudah diberi promosi kesehatan dengan media film pada siswa di SMPN 226 Pondok Labu Jakarta Selatan $(p$-value $<0,05)$ dan terjadi peningkatan median dari sebelum promosi kesehatan yaitu 86,67 menjadi 93,33 setelah diberi promosi kesehatan dengan media film.

Tabel 3. Perbandingan Nilai Sebelum dan Sesudah Promosi Kesehatan dengan Media Film di SMPN 226 Pondok Labu Jakarta Selatan

\begin{tabular}{lcccc}
\hline & $\mathrm{N}$ & $\begin{array}{c}\text { Median } \\
\text { (Minimum-Maksimum) }\end{array}$ & Rerata \pm SD & $\begin{array}{c}\mathrm{p}- \\
\text { value }\end{array}$ \\
\hline Pengetahuan sebelum promosi kesehatan & 108 & $86,67(46,67-100)$ & $83,46 \pm 13,47$ & 0,000 \\
Pengetahuan sesudah promosi kesehatan & 108 & $93,33(40-100)$ & $89,38 \pm 10,98$ & 0,000 \\
\hline
\end{tabular}

Tabel 4. Menunjukkan bahwa tidak terdapat perbedaan pengetahuan antara sesudah promosi kesehatan dengan media leaflet dan media film. Selain itu, juga tidak terdapat perbedaan efektivitas dalam peningkatan pengetahuan pubertas antara media leaflet dan media film pada siswa di SMPN 226 Pondok Labu Jakarta Selatan.

Tabel 4. Perbandingan Promosi Kesehatan antara Media Leaflet dan Media Film di SMPN 226 Pondok Labu Jakarta Selatan

\begin{tabular}{lccccc}
\hline & & $N$ & $\begin{array}{c}\text { Median } \\
\text { (Minimum-Maksimum) }\end{array}$ & Rerata \pm SD & $\begin{array}{c}\mathrm{p}- \\
\text { value }\end{array}$ \\
\hline $\begin{array}{l}\text { Pengetahuan sesudah promosi } \\
\text { kesehatan dengan media leaflet }\end{array}$ & 148 & $93,33(20-100)$ & $89,82 \pm 14,09$ & \\
$\begin{array}{l}\text { Pengetahuan sesudah } \\
\text { kesehatan dengan media film }\end{array}$ & promosi & 108 & $93,33(40-100)$ & $89,38 \pm 10,98$ & 0,083 \\
\hline
\end{tabular}

Disease Prevention and Public Health Journal

Volume 14, Issue 1, March 2020: $46 \sim 50$ 
3.2 Pembahasan

Meningkatkan pengetahuan perlu adanya pemberian informasi yang menurut WHO merupakan salah satu strategi untuk memdapatkan perubahan perilaku. Salah satu upaya pemberian informasi adalah dengan menggunakan media leaflet.(8) Leaflet merupakan salah satu bentuk dari media promosi kesehatan visual-aid yang memiliki salah satu manfaat yaitu untuk mempermudah penerimaan informasi bagi sasaran pendidikan. Media promosi kesehatan akan sangat membantu agar pesan-pesan yang disampaikan dalam promosi kesehatan dapat diberikan dengan jelas sehingga sasaran dapat menerima pesan dengan jelas dan tepat yang dapat terlihat dengan terjadinya peningkatan nilai pengetahuan.(6)

Penelitian ini sejalan dengan penelitian sebelumnya dimana terjadi peningkatan nilai mean pengetahuan sebelum dan sesudah pemberian promosi kesehatan melalui media leaflet. Hal ini dapat terjadi karena penyajian dalam leaflet tersebut sudah cukup jelas sehingga dapat dibaca dan dipahami dengan baik.(9) Penelitian lainnya juga menyatakan bahwa terdapat peningkatan pengetahuan dengan menggunakan leaflet serta ada perbedaan pengetahuan sebelum dan sesudah menerima penyuluhan dengan menggunakan leaflet.(10-12)

Media audio visual seperti film merupakan jenis media yang selain mengandung unsur suara juga mengandung unsur gambaran yang dapat dilihat, seperti rekaman vidio, slide suara dan lain sebagainya.(6) Kemampuan media audio visual ini dianggap lebih baik dan menarik, sebab mengandung kedua unsur, yaitu didengar dan dilihat. Pancaindera yang banyak menyalurkan pengetahuan ke otak adalah mata ( $\leq 75 \%-87 \%)$, sedangkan $13 \%$ sampai $25 \%$, pengetahuan manusia diperoleh dan disalurkan melalui panca indera yang lain. Penelitian ini selaras dengan penelitian sebelumnya yang menyatakan bahwa terdapat perbedaan antara pengetahuan dan sikap sebelum dan sesudah menerima penyuluhan dengan menggunakan media film. Selain itu, media film juga efektif untuk meningkatkan pengetahuan dan sikap remaja.(13-16).

Adapun penelitian ini sesuai dengan penelitian terdahulu yang menyatakan tidak ada perbedaan efektivitas antara leaflet dan media film dalam promosi kesehatan terhadap peningkatan pengetahuan dan sikap pada remaja. $(7,17,18)$ Namun, penelitian ini tidak sejalan dengan penelitian terdahulu yang menyatakan promosi kesehatan melalui audio visual lebih efektif daripada menggunakan leaflet dan media audiovisual juga lebih meningkatkan pengetahuan dibandingkan menggunakan leaflet.(19) Penelitian ini juga tidak sesuai dengan penelitian lainnya yang menyatakan peningkatan pengetahuan menggunakan media film lebih efektif dibanding menggunakan media leaflet dan terdapat perbedaan mean selisih pengetahuan media leaflet dan media film.(20)

\section{Kesimpulan}

Berdasarkan uraian diatas dapat disimpulkan bahwa media leaflet dan film efektif meningkatkan pengetahuan pubertas, namun tidak terdapat perbedaan efektivitas antara media leaflet dan media film dalam meningkatkan pengetahuan pubertas pada siswa SMPN 226 Pondok Labu Jakarta Selatan. Disarankan media leaflet dan media film dapat digunakan sebagai media promosi kesehatan karena terbukti efektif untuk meningkatkan pengetahuan. Hasil ini dapat digunakan untuk penelitian selanjutnya dengan topik kesehatan reproduksi lainnya.

\section{Daftar Pustaka}

1. Sawyer SM, Azzopardi PS, Wickremarathne D, Patton GC. The age of adolescence. Lancet Child Adolesc Heal. 2018;2(3):223-8.

2. Fikawati S, Ahmad S, Veratamala A. Gizi Anak dan Remaja. 1st ed. Depok: PT Radjagrafindo Perkasa; 2017. 127-148 p.

3. Kusumawati PD, Ragilia S, Trisnawati NW, Larasati NC, Laorani A, Soares SR. Edukasi Masa Pubertas pada Remaja. J Community Engagem Heal. 2018;1(1):14-6.

4. Tim SDKI 2017. Survei Demografi Dan Kesehatan Indonesia 2017: Kesehatan Reproduksi Remaja. BPS, BKKBN, Kemenkes, USAID, editors. Badan Kependudukan dan Keluarga Berencana Nasional; 2018. 19 p.

5. Patonah S, Setiawan A, Setiyani ME. Pengaruh Penyuluhan terhadap Pengetahuan 
Remaja Putri tentang tanda-tanda Pubertas di Kelas VII SMP Al-Maliki Desa Ledok Wetan Kecamatan Bojonegoro Kabupaten Bojonegoro Tahun 2014. Asuhan Kesehat J IIm IImu Kebidanan dan Keperawatan. 2016;7(1):8-13.

6. Notoatmodjo S. Promosi Kesehatan dan IImu Perilaku. Jakarta: Rineka Cipta; 2014.

7. Yustisa PF, Aryana IK, Suyana ING. Efektivitas Penggunaan Media Cetak Dan Media Elektronika dalam Promosi Kesehatan terhadap Peningkatan Pengetahuan dan Perubahan sikap Siswa SD. J Kesehat Lingkung. 2014;4(1):29-39.

8. Tindaon RL. Pengaruh Komunikasi, Informasi, dan Edukasi (KIE) melalui Media Leaflet dan Video terhadap Pengetahuan dan Sikap Remaja tentang Paparan Pornografi di SMP Negeri 1 Sidamanik Kec. Sidamanik Kab. Simalungan Tahun 2016. Jumantik. 2018;3(1):44-64.

9. Susanti N, Qodariah, Yessi H, Rasyid Z. Efektifitas Leaflet terhadap Pengetahuan dan Mengatur Pola Makan LansiaPenderita Hipertensi di Puskesmas Serasan Kabupaten Natuna. J Phot. 2017;7(2):33-8.

10. Fauziah AN, Maesaroh S, Sulistyorini E. Penggunaan leaflet terhadap peningkatan pengetahuan tentang pemeriksaan payudara sendiri (SADARI). Gaster| J IImu Kesehat. 2017;15(2):204-15.

11. Andarmoyo S. Pemberian Pendidikan Kesehatan melalui Media Leaflet dalam Peningkatan Pengetahuan Perilaku Pencegahan Tuberkulosis Paru di Kabupaten Ponorogo. Pros Semin Nas Pendidik. 2015;(November):600-5.

12. Sistiarani C, Dardjito E, Siti N. Educational Leaflet to improve Mother Knowledge about Utilization of "Maternal and Child Health Book" in Kalibagor, Indonesia. Manag Heal. 2015;XIX(1):24-8.

13. Nanda RO, Nasution E, Sudaryati E. Pengaruh Penyuluhan Gizi tentang Pencegahan Obesitas dengan Media Film Animasi terhadap Peningkatan Pengetahuan dan Sikap Anak Sekolah SD Muhammadiyah 01 Pematang Siantar. Gizi, Kesehat Reproduksi dan Epidemiol. 2017;1(1):1-8.

14. Mariani NN, Lisnawati L. Pendidikan Kesehatan Berbasis Multimedia Berpengaruh Terhadap Pengetahuan Tentang Kesehatan Reproduksi Siswa. Care J IIm IImu Kesehatan. 2018;6(3):210-8.

15. Auliyah A, Flurentin E. Efektifitas Penggunaan Media Film Untuk Meningkatkan Empati Siswa Kelas VII SMP. J Kaji Bimbing dan Konseling. 2016;1(2):19-26.

16. Sasmitha NR, Auli Ilmi A, Huriati. Peningkatan Pengetahuan tentang Cuci Tangan melalui Pendidikan Kesehatan dengan Media Audiovisual. J Islam Nurs. 2017;2(2):4351.

17. Susetya DRS, Dewi ER. Efektivitas Media Film dengan Leaflet dalam Peningkatan Pengetahuan Ibu Rumah Tangga tentang DBD di Desa Pekalongan Kabupaten Pati. J Kesehat Masy Cendikia Utama. 2018;6(1):3.

18. Yuniwati C, Yusnaini, Khatimah K. Pengaruh Media Audio Visual Dan Media Leaflet Terhadap Tingkat Pengetahuan Remaja Mas Darul Ihsan Aceh Besar Tentang Hiv / Aids. J IIm PANNMED. 2017;13(2):116-20.

19. Alini I. Efektifitas Promosi Kesehatan Melalui Audio Visual Tentang Pemeriksaan Payudara Sendiri (SADARI) Terhadap Peningkatan Pengetahuan Remaja Putri. J Ners Univ Pahlawan. 2018;2(2):1-9.

20. Suhertusi B, Desmiwarti, Nurjasmi E. Pengaruh Media Promosi Kesehatan tentang ASI Eksklusif terhadap Peningkatan Pengetahuan Ibu di Wilayah Kerja Puskesmas Lubuk Begalung Padang Tahun 2014. J Kesehat Andalas. 2015;4(1):17-22. 